\title{
Identification of genes and gene expression associated with dispersal capacity in the mountain pine beetle, Dendroctonus ponderosae Hopkins (Coleoptera: Curculionidae)
}

\author{
Victor A Shegelski ${ }^{\text {Corresp., } 1}$, Maya L Evenden ${ }^{1}$, Dezene P W Huber ${ }^{2}$, Felix A H Sperling ${ }^{1}$ \\ ${ }^{1}$ Department of Biological Sciences, University of Alberta, Edmonton, Alberta, Canada \\ 2 Faculty of Environment, University of Northern British Columbia, Prince George, British Columbia, Canada \\ Corresponding Author: Victor A Shegelski \\ Email address: shegelsk@ualberta.ca
}

Dispersal flights by the mountain pine beetle have allowed range expansion and major damage to pine stands in western Canada. We asked what the genetic and transcriptional basis of mountain pine beetle dispersal capacity is. Using flight mills, RNA-seq and a targeted association study, we compared strong-flying, weak-flying, and non-flying female beetles from the recently colonized northern end of their range. Nearly 3000 genes were differentially expressed between strong and weak flying beetles, while weak fliers and nonfliers did not significantly differ. The differentially expressed genes were mainly associated with lipid metabolism, muscle maintenance, oxidative stress response, detoxification, endocrine function, and flight behavior. Three variant loci in the coding regions of genes were significantly associated with flight capacity but these genes had no known functional link to flight. Several differentially expressed gene systems may be important for sustained flight, while other systems are downregulated during dispersal and likely to conserve energy before host colonization. The candidate genes and SNPS identified here will inform further studies and management of mountain pine beetle, as well as contribute to understanding the mechanisms of insect dispersal flights. 


\section{Introduction}

2 Flight-based dispersal in insects is influenced by many biotic, abiotic, temporal and spatial

3 factors (Stinner et al. 1983; Bowler and Benton 2005; Jones et al. 2019). Individual insects

4 respond to these factors with physiological, morphological, and behavioral adaptations that

5 determine their flight capabilities (Roff and Fairbairn 2007; Jones et al. 2019). In many insects,

6 flight and dispersal capacity may manifest as discrete differences between dispersal and non-

7 dispersal types (Zhang et al. 2019), but, in others, such as mountain pine beetle, dispersal

8 distance is a continuous trait (Shegelski et al. 2019). In another dispersing pest species, the

9 cotton bollworm, Helicoverpa armigera, such continuous traits associate with large suites of

10 genes (Jones et al. 2015). Disentangling the mechanisms that underlie flight capacity can provide

11 valuable insights into the dispersal and spread of economically important insect species

12 (Kristensen et al. 2013; Portman et al. 2020).

13 Mountain pine beetles, Dendroctonus ponderosae Hopkins (Coleoptera: Curculionidae:

14 Scolytinae), contribute to the maintenance of healthy pine forests (Safranyik and Carroll 2006),

15 but can cause significant damage during major outbreaks (Hart et al. 2015). The most recent

16 outbreak in western Canada breached the Northern Rocky Mountains (de la Giroday et al. 2012)

17 and expanded the range of the mountain pine beetle to include a novel host tree, jack pine, Pinus

18 banksiana Lamb. (Cullingham et al. 2011), which has a distribution that extends through the

19 boreal forest toward further pine hosts in eastern Canada and USA.

20 Morphology is a significant indicator of flight capacity by mountain pine beetles (Evenden et al.

21 2014; Shegelski et al. 2019); however, many beetles with strong flight-related morphology

22 actually fly very little, displaying a large amount of unexplained variation in flight performance 
23 (Shegelski et al. 2019). Genetic factors constitute a plausible component of this variation.

24 Numerous genes that relate to other life phases and processes of mountain pine beetles have been

25 identified, including pheromone biosynthesis (Keeling, Chiu, et al. 2013; Nadeau et al. 2017), overwintering cold tolerance (Bonnett et al. 2012; Robert et al. 2016; Fraser et al. 2017), detoxification of host defenses and reproduction (Robert et al. 2013; Pitt et al. 2014; Huber and Robert 2016). However, the dispersal phase of these beetles remains essentially unexplored from a genomic standpoint.

Our study aimed to identify genetic correlates of dispersal capacity in mountain pine beetles. Dispersal-related genes in other insects have been linked to regulation of metabolic rate (Wheat et al. 2010; Jones et al. 2015; Zhou et al. 2020), muscle tracheation (Marden et al. 2013), generally improved flight capability (Niitepõald et al. 2009; Wheat et al. 2010), and increased dispersal behavior (Zhou et al. 2020). We sought to determine what suites of genes are most associated with flight and dispersal-related functions in mountain pine beetles. To achieve this, we combined a computer-linked flight mill bioassay with differential gene expression analysis using RNA-Seq and a subsequent targeted association study. The identification of flight-related genes will allow better understanding of the mechanisms associated with insect flight and dispersal and potentially lead to more effective management of the spread of mountain pine beetle, in both its established and newly expanded ranges.

\section{Methods}

Sample collection and preparation. Four lodgepole pine trees infested with mountain pine beetles were selected from sites near Grande Prairie, Alberta, Canada (three trees from Site 1 at 54.57 N, 119.42 W; and one tree from Site 2 at 54.19 N, 118.68 W) in October 2015. Two 50-cm 
45 bolts were cut from each tree at about $1 \mathrm{~m}$ above ground level. The cut ends of the bolts were

46 sealed with paraffin wax upon felling, and bolts were transported to a laboratory and stored at

$47 \quad 4^{\circ} \mathrm{C}$ for six months, to emulate winter conditions.

48 For beetle emergence, bolts were placed in separate $136 \mathrm{~L}$ opaque plastic emergence chambers at

$4924 \pm 1^{\circ} \mathrm{C}$ in April 2016, and emerged beetles were collected daily. Individual beetles were

50 separated by sex based on the presence or absence of beetle stridulation at $24 \pm 1^{\circ} \mathrm{C}$, using the

51 methods of Rosenberger et al. (2016). In order to reduce metabolic expenditures of beetles before

52 flight, individual beetles were stored at $4^{\circ} \mathrm{C}$ in $2 \mathrm{~mL}$ centrifuge tubes with a small piece of paper

53 until the flight bioassay (Evenden et al. 2014), which was performed three to five days post-

54 emergence.

55 Flight mill bioassay and sample selection. Only female mountain pine beetles were used in this

56 study, as females initiate host location in nature (Blomquist et al. 2010), and we wanted to

57 control for potential effects of sex both in the bioassays and in subsequent analyses. Prior to

58 flight bioassays, female beetles were weighed and measured at $24 \pm 1^{\circ} \mathrm{C}$ for a separate

59 morphological analysis (Shegelski et al. 2019). Beetles were then attached to individual $2 \mathrm{~cm}$

60 long aluminum wire tethers with a diameter of $0.32 \mathrm{~mm}$. LePage ${ }^{\circledR}$ Heavy Duty Contact Cement

61 was used to adhere the tether to the pronotum of each individual, taking care to avoid

62 interference with wing or elytral movement.

63 A total of 124 female beetles were flown on flight mills. Data was recorded on flight distance,

64 duration (time spent in flight) and propensity (the number of times flight was initiated after a

65 minimum 5 second period of no flight), using methods for computer-linked flight mill bioassays

66 described by Evenden et al. (2014). The flight bioassays were 22 hours long, which allowed a 2- 
67 hour period for specimen processing. Conditions in the flight chamber consisted of a 16:8

68

69

light:dark photoperiod and temperature held at $22.5^{\circ} \mathrm{C}$. Flights began two hours after the initiation of the photoperiod light phase in the chamber, giving specimens a total of 14 hours of potential flight time in light, and 8 hours in dark.

The seven beetles with the highest and seven with the lowest total flight distances were used to represent the strongest and the weakest fliers, respectively. In addition, four beetles that did not fly, but demonstrated vigor and a full range of motion in the elytra and wings, were selected to represent non-fliers. Selected beetles were flash frozen in liquid nitrogen after the flight bioassay and stored at $-80^{\circ} \mathrm{C}$ until RNA extraction. All other assayed beetles were stored at $-20^{\circ} \mathrm{C}$ in $85 \%$ EtOH until use. Three voucher specimens from the same location have been submitted to the E.H. Strickland Entomological Museum at the University of Alberta, Canada (Accession numbers UASM391992, UASM391993 and UASM391994).

Samples for the association study included 59 female beetles taken from the remaining specimens that were not used for other analyses. This included a total of 31 strong and 28 weak fliers that were randomly selected from the upper and lower quartiles of total flight distance.

RNA extractions, RNA-Seq library preparation \& sequencing. We used Zymo Research direct-zol RNA MiniPrep kits for total RNA extractions, with a DNase I treatment and Invitrogen TRIzol as a medium for specimen homogenization. RNA quality was checked using an Agilent 2100 Bioanalyzer system and quantified using Invitrogen Qubit RNA fluorometric quantification. cDNA synthesis and RNA-seq library preparation used an IlluminaTruSeq Stranded RNA LT Kit and followed the recommended protocol, which included poly-A selection for mRNA purification. Prior to sequencing, quality and quantity of cDNA was checked again 
89

90

91

92

using an Agilent 2100 Bioanalyzer. Library sequencing was performed on an Illumina NextSeq 500 platform at the Molecular Biology Service Unit (MBSU) at the University of Alberta. Sample groups were evenly split between two NextSeq 500 runs to provide an optimal number of reads.

Sequence data mapping $\&$ differential expression analysis. Our experiment included 18 female beetles belonging to three flight phenotypes (seven strong fliers, seven weak fliers, and four non-fliers. The male mountain pine beetle genome (Keeling, Yuen, et al. 2013) was used for alignment of sequence data as it contains 1504 more genes than the female genome. This difference is largely due to the presence of Y chromosome fragments but may also include some autosomal genes of importance. Sequence data was aligned using Bowtie2 version 2.1.1.3 (Langmead and Salzberg 2012) and Tophat2 version 2.1.1 (Kim et al. 2013), with a maximum of five alignment sites, and otherwise default settings. These data were then sorted and indexed using SAMtools version 1.5 (Li et al. 2009).

Differential expression analysis was performed using the R package DESeq2 (Love et al. 2014), in $\mathrm{R}$ version 3.3.3 (R Core Team 2017). We chose to use DESeq2 for its stringency (Rajkumar et al. 2015), potentially causing more false negatives (Type II error) than false positives (Type I error). BAM files were read using RSamtools (Morgan et al. 2017) and annotated read count tables were produced using the packages GenomicFeatures and GenomicAlignments (Lawrence et al. 2013). Differentially expressed genes with a false discovery rate $(F D R)<0.01$ were considered candidate genes related to flight. A principal component analysis (PCA) was performed on regularized logarithm-transformed gene expression data to visualize relationships 
110 between the specimens based on gene expression without bias towards highly expressed genes

111 (Love et al., 2014).

112 Enrichment analysis \& KEGG pathway analysis. We used Blast2GO version 5.2.5 (Götz et

113 al. 2008) to identify trends in gene ontology (GO) annotations and Kyoto Encyclopedia of Genes

114 and Genomes (KEGG; Kanehisa and Goto, 2000) pathways for the differentially expressed gene

115 transcripts. Nucleotide sequences of these transcripts were blasted to the NCBI nr database,

116 retaining the three best hits and otherwise using default search parameters. Transcript sequence

117 data was mapped and annotated with GO terms, then also annotated based on the Interpro

118 database to validate GO annotations. Enrichment analysis using Fisher's exact test (FDR $<0.05$ )

119 tested upregulated and downregulated genes separately for significant overrepresentation of GO

120 terms between the strong and weak flight phenotypes. KEGG pathway analysis was also

121 performed on all differentially expressed transcripts to identify flight-related pathways.

122 Association study: DNA extractions, sequencing \& mapping. DNA extractions for 59 female

123 beetles used a Qiagen DNEasy Blood \& Tissue kit, following standard protocol with an optional

124 RNAse A treatment and library preparation using the ddRAD protocol of Peterson et al. (2012).

125 Single-end sequencing was performed at the University of Alberta MBSU using the Illumina

126 NextSeq500 platform. Initial data processing and quality checking of the raw sequence data

127 followed protocols by Campbell et al. (2017).

128 A common weakness of association studies is the large number of comparisons may diminish

129 power (Visscher et al. 2017). To increase statistical power, we reduced the number of tested loci

130 by focusing on candidate regions identified through our RNA-seq experiment. Alignment for the

131 association study used the subset of scaffolds from the male mountain pine beetle draft genome

Peer] reviewing PDF | (2021:07:63558:1:0:NEW 21 Sep 2021) 
132 (Keeling, Yuen, et al. 2013) that contained one or more flight-related genes based on our

133 differential gene expression analysis. This alignment used the BWT-SW algorithm in BWA

134 version 0.7.17 (Li and Durbin 2009), and alignment quality was checked using SAMtools

135 version 1.9 (Li et al. 2009).

136 Stacks 2.0 ref_map.pl (Rochette et al. 2019) was used to identify single nucleotide

137 polymorphism (SNP) sites. We allowed a minor allele frequency of $1 \%$, and loci were initially

138 retained if they were present in at least $80 \%$ of the 59 specimens (Paris et al. 2017). Further

139 filtering used vcftools version 0.1.14 (Danecek et al. 2011), with reads with a genotype quality

140 score below 30 and SNP sites with more than 2\% missing data among individuals excluded from

141 the final data set.

142 Targeted association study. We used TASSEL version 5.2.54 (Bradbury et al. 2007) to perform

143 an association study in which we tested SNP sites for associations with total flight distance as

144 well as flight propensity, which is likely an important predictor of realized dispersal in nature

145 (Steyn et al. 2016). For this study we used 31 strong and 28 weak fliers. SNP sites with

146 heterozygosity in less than $5 \%$ or greater than $95 \%$ of the samples were filtered, as these sites

147 may represent genotyping errors (Leal 2005). We used identity by state to account for

148 relatedness between individuals, a principal component analysis (PCA) to account for population

149 structure and stratification, and a generalized linear model (GLM) with permutation testing

150 (1000 permutations) to account for non-normal distributions in the phenotypic data and FDR

151 (Che et al. 2014). The permutated p-value (perm p) was used to determine significance at

$152 \alpha=0.05$. 


\section{Results}

154 Flight mill bioassay. A summary of the bioassay results can be seen in Table 1 and Fig. 1. On 155 average, female beetles from all flight bioassays $(n=124)$ flew $7.4 \mathrm{~km}$ and initiated flight 176 156 times. Beetles specifically used for the differential expression analysis ( $\mathrm{n}=14$, excluding non-

157 fliers) flew an average of $10.08 \mathrm{~km}$ and initiated flight an average of 72.8 times. Beetles selected 158 to represent the strong flight phenotype had an average flight distance of $19.9 \mathrm{~km}$ and initiated 159 flight an average of 83.9 times, while the group representing the weak flight phenotype flew $160 \quad 0.231 \mathrm{~km}$ on average and initiated flight an average of 61.7 times. There was a significant 161 difference in total flight distance between strong $(n=7)$ and weak $(n=7)$ flight phenotypes $(t$ 162 stat $=8.2, \mathrm{df}=6, \mathrm{P}<0.0001$ ), but there was no significant difference in flight propensity (the 163 number of times flight was initiated) ( $\mathrm{t} s t a t=-0.45, \mathrm{df}=10, \mathrm{p}=0.333)$. Although the majority $164(88.5 \%)$ of flight by these beetles took place during the light period, beetles with a strong flight 165 capacity flew significantly more in the dark than did weak fliers ( $\mathrm{t}$ stat $=2.253, \mathrm{df}=12, \mathrm{p}=0.0218$;

166 Fig. 2). On average, strong fliers flew $84.4 \%$ of their total flight time in the light, and $15.6 \%$ in

167 the dark. This compared to weak fliers that on average flew $95.6 \%$ of their total flight time in the 168 light, and $4.4 \%$ in the dark.

169 The 59 female beetles used for the association study flew an average of $6.4 \mathrm{~km}$ and initiated 170 flight an average of 229.8 times. The strong fliers used for the association study flew 171 significantly farther than the weak fliers ( $\mathrm{stat}=12.3, \mathrm{df}=57, \mathrm{p}<0.001)$. The strong flight beetles 172 in this data set $(n=31)$ flew an average of $11.4 \mathrm{~km}$, and the weak fliers $(n=28)$ flew an average of $1730.8 \mathrm{~km}$. There was no significant difference in flight propensity, however, between the strong 174 and weak fliers used for the association study $(\mathrm{t}$ stat $=1.1, \mathrm{df}=57, \mathrm{p}=0.297)$ (Table 1$)$. 
175 Differential expression analysis. A total of 1.735 billion reads were sequenced via RNA-Seq,

176 and 1.283 billion reads were $>$ Q30. On average, there were 65.5 million reads per sample, and

177 this ranged from 25.2 million reads to 108.8 million reads (Table 1). Principal component

178 analysis of variation in gene expression by the three phenotypes (strong, weak \& non-fliers)

179 showed a clear separation of strong fliers from weak and non-fliers. It also showed substantial

180 overlap between non-fliers and weak fliers, with weak fliers having the highest variation in gene

181 expression (Fig. 3A). No genes were significantly differentially expressed between weak fliers

182 and non-fliers (Fig. 3B), and further analyses focused on the differences between strong and

183 weak fliers. The list of differentially expressed genes between strong and non-fliers is in Table

184 S1.

In comparisons of strong to weak fliers, differential expression analysis using DESeq2 revealed 2741 differentially expressed genes (Fig. 3C; Table S1). Of these, 1486 (54.2\%) of the genes were upregulated and $1255(45.8 \%)$ were downregulated. Of the differentially expressed genes, 387 were uncharacterized. In this study, we focus on genes that could be broadly categorized as relating to metabolism (resource consumption and energy production), muscle form and function (physical structure and components of flight muscle), oxidative stress and detoxification (ability to remove metabolic wastes during flight), the endocrine system (regulation of flight-related physiological and behavioral mechanisms), and flight behavior (those affecting innate response and inclination relating to flight) (summarized in Table S2).

We identified 20 genes related to various stages of lipid metabolism, and all but three were upregulated with flight (Table S2). The majority were lipases, although there were also reductases and dehydrogenases, among others. 
197 We found 15 differentially expressed genes relating to muscle form and function (Table S2),

198 including four collagen alpha chains (all upregulated with flight), and five related to myosin (two

199 upregulated with flight and three downregulated), including paramyosin, which is structurally

200 integral to indirect flight muscle (Liu et al. 2003). We also found six differentially expressed

201 myotubularin transcripts (three upregulated with flight and three downregulated with flight),

202 which relate to muscle maintenance (Laporte et al. 2001).

203 We identified 10 differentially expressed genes involved in oxidative stress management (Table

204 S2), including five glutathione S-transferases (GSTs; one theta, three sigma, one ambiguous

205 Delta/Epsilon), one microsomal GST, and four antioxidants (two phospholipid hydroperoxide

206 glutathione peroxidases, and two peroxiredoxins). We also found 23 differentially expressed

207 cytochrome P450 genes, including seven CYP4s, nine CYP6s, three CYP9s, two CYP307s, one

208 CYP 302, and one CYP 28. Also related to stress response, we identified seven heat shock

209 protein transcripts that were differentially expressed.

210 There were 10 transcripts related to endocrine function, including four related to juvenile

211 hormone (JH) and ecdysone systems, and six related to insulin and insulin-like growth factor

212 (IGF; Table S2). Both JH-related genes were upregulated; these both coded for juvenile hormone

213 epoxide hydrolase (JHEH), which deactivates JH. There was upregulation of ecdysone 20-

214 monooxygenase, which catalyzes production of the hormone 20-hydroxyecdysone (20E), and the

215 ecdysone-inducible protein E75, an orphan hormone receptor (Segraves and Hogness 1990), was

216 downregulated. Insulin is involved in metabolism, growth, and development (Nässel et al. 2015).

217 Of the six insulin family-related genes, there were four upregulated receptors (two insulin 
218 receptors and two insulin-like growth factor receptors), one downregulated insulin-degrading

219 enzyme, and one downregulated insulin-like growth factor-binding protein.

220 Some potential behavioral genes that were differentially expressed included two isoforms of

221 nocturnin, which relates to light-mediated behavioral response, a circadian clock-controlled

222 protein, and protein alan shepard, which is related to gravitaxis (Armstrong et al., 2006; Table

223 S2).

224 Nine differentially expressed transcripts were related to olfaction (Table S2). Of these,

225 transcripts for two chemosensory proteins, three odorant receptors, and two odorant-binding

226 proteins were downregulated with flight, and two odorant binding-protein transcripts were

227 upregulated with flight.

228 GO enrichment analysis. Of the 2741 differentially expressed gene transcripts, $2556(93.3 \%)$ of

229 the transcripts had InterPro hits, and 1358 (49.5\%) had one or more GO annotations. Enrichment

230 analysis of upregulated GO terms was performed in two categories - biological process and

231 molecular function. The 100 significantly overrepresented GO terms ( 89 biological processes

232 and 11 molecular functions; FDR=0.05), were condensed to 25 related GO terms with more

233 specific functions. These included eight molecular functions and 17 biological processes relating

234 to oxidoreductase activity, coenzyme binding, oxidation-reduction processes, mitochondrial

235 transport and organization, and coenzyme metabolic processes (Fig. 4).

236 Enrichment analysis of the downregulated GO terms revealed 28 overrepresented terms (24

237 biological processes and four molecular functions; FDR=0.05), which were reduced to four more 
238 specific GO terms, including two molecular functions and two biological processes related to

239 DNA transcription and signal transduction (Fig. 4).

240 KEGG pathways. KEGG pathway analysis of all differentially expressed genes revealed 52

241 pathways represented by at least two enzymes, 42 of which were represented by at least three

242 enzymes (Fig. 5). Several metabolic pathways included: the metabolism of glycerolipids, purine,

243 pyruvate, and sphingolipids, pantothenate and coenzyme A biosynthesis, glycolysis, and the

244 citric acid cycle. Detoxification and stress response were also represented in the KEGG

245 pathways, including detoxification, biosynthesis of antibiotics, drug metabolism, and metabolism

246 of xenobiotics by cytochromes P450. We also found pathways associated with glutathione

247 metabolism, which may relate to oxidative stress. The steroid hormone biosynthesis pathway,

248 which may relate to hormone-mediated flight behaviors, was also represented, but only by three

249 sequences that all coded for the same enzyme.

250 Targeted association study. We identified 714 scaffolds containing differentially expressed

251 flight genes. Of these, 347 scaffolds contained no SNPs, and the remaining 367 scaffolds

252 contained a total of 6643 ddRAD SNP sites that passed filtering. From these, three SNPs were

253 significantly associated with flight performance: two were associated with flight distance (Fig.

254 6A), and one associated with flight propensity (Fig. 6B). Of the two SNPs associated with flight

255 distance, the first is located at position 3148638 on scaffold NW_017852012 (perm p=0.043), in

256 an exon (XM_019902532) in gene LOC109536350 (Protein Brunelleschi). Beetles that are

257 homozygous $\mathrm{C}(\mathrm{n}=6)$ at this position are estimated to fly $1.06 \mathrm{~km}$ further than those that are

258 heterozygous at this position $(n=31)$, while those that are homozygous $\mathrm{T}(\mathrm{n}=21)$ are estimated to

259 fly $7.4 \mathrm{~km}$ less than heterozygous beetles. Although this SNP is in a coding region, it does not 
260 result in a change of amino acid. The second SNP associated with flight distance is located at

261 position 786674 on scaffold NW_017852312 (perm p=0.045), in an intron of an uncharacterized

262 gene, LOC109543163. Beetles that are homozygous A $(n=44)$ at this position are estimated to fly

$2638.11 \mathrm{~km}$ less than those that are heterozygous at this position $(\mathrm{n}=14)$, and there were no beetles

264 that were homozygous $\mathrm{G}$ at this site.

265 The SNP associated with flight propensity is located at position 188406 on scaffold

266 NW_017851689 (perm p=0.046) and is located in an intron of the gene LOC109534071 (WD

267 repeat-containing protein 55 homolog). Beetles that are homozygous $\mathrm{T}(\mathrm{n}=2)$ at this position are

268 estimated to initiate flight 2173 more times than those that are heterozygous at this position

$269(n=27)$, while those that are homozygous $C(n=30)$ are estimated to initiate flight 68 fewer times

270 than heterozygous beetles.

\section{Discussion}

272 Dispersal by flight is an important phase in the life history of many insects (Roff and Fairbairn

273 2007). In the case of tree-killing bark beetles in their epidemic population phase, dispersal is

274 mandatory for brood production (Raffa et al. 2015). Our study shows that several genetic

275 systems are associated with strong flight in the mountain pine beetle, with gene expression

276 profiles of strong flying beetles being significantly different from both weak flying and non-

277 flying beetles (Fig. 3); however, no significant differences were found between the weak fliers

278 and non-fliers (Fig. 3), indicating that the physiological difference between non-fliers and weak

279 fliers is minimal. Based on this, and in order to retain equal sample sizes, we focused on the

280 differences between strong and weak fliers. Because we focus on associations, it is important to 
281 note that many of these genes may be a consequence of strong flight, rather than a contributor to 282 it.

283 Metabolism. Upregulated metabolic activity is expected for insect flight, as it is one of the most 284 physiologically demanding activities known (Wegener 1996). Several GO terms and KEGG 285 pathways indicate the importance of metabolic processes, such as glycolysis, citric acid cycle, 286 and serine metabolism. Serine, in particular, is associated with the metabolism of lipids (Gao et

287

al. 2018), a known energy source in insects and a major fuel source for sustained flight in mountain pine beetles (Evenden et al. 2014; Wijerathna and Evenden 2019). This is supported by several upregulated lipid metabolism-related genes and pathways (Table S2; Fig. 5).

Muscle form \& function. Differential expression of flight muscle-related genes affects flight capabilities in two armyworm species (Spodoptera eridania and Spodoptera frugiperda; Portman et al. 2020). We identified several differentially expressed genes that indicate the importance of muscle function and maintenance in flight in mountain pine beetle. We identified differentially expressed collagen genes, which are important for muscle development and function in monarch butterflies (Danaus plexippus; Zhan et al. 2014) and link to long distance flight behavior in insects such as the monarch butterfly (Zhan et al. 2014) and cotton bollworm (Helicoverpa armigera; Jones et al. 2015). Some myosins were also related to flight; in particular, paramyosin was upregulated in strong fliers, and is known to be structurally integral to thick filaments in the indirect flight muscle of Drosophila (Drosophila melanogaster; Liu et al. 2003). These genes may act in concert with various up and down regulated myotubularin genes in order to maintain muscle structure and function during bouts of sustained flight (Laporte et al. 2001). 
302 Oxidative Stress and Detoxification. Our data suggest several mechanisms are used by

303 mountain pine beetles to mitigate stress-induced cellular damage during flight, including DNA

304 repair pathways and GSTs. In strong fliers, DNA repair genes, supported by GO terms, are

305 upregulated and would mitigate genomic damage caused by oxidative stress (Fig. 4). Also, GSTs

306 are antioxidants (Pompella et al. 2003; Yamamoto et al. 2011; Yamamoto et al. 2016) and

307 prevent build-up of potentially harmful byproducts of lipid metabolism in the flight muscle of

308 Drosophila (Singh et al. 2001). Upregulated GSTs and other glutathione-related pathways in

309 strong female fliers may play other roles in successful dispersal and establishment, as females

310 are the pioneering sex in the mountain pine beetle (Blomquist et al. 2010). For instance, GSTs

311 are involved in detoxification of host defenses during colonization (Keeling, Yuen, et al. 2013;

312 Robert et al. 2013), and this process often involves precursor steps that rely on reactions with

313 other enzymes, such as cytochromes P450 (Sheehan et al. 2001).

314 Several cytochromes P450 are differentially expressed in strong fliers, and these are found

315 mostly in three cytochrome P450 families (CYP4, CYP6, and CYP9). These families are

316 believed to be environmentally adaptive due to lineage-specific gene family expansions found in

317 the mountain pine beetle when compared to Tribolium castaneum (Keeling, Yuen, et al. 2013).

318 Many of these are likely involved in host defense detoxification (Sandstrom et al. 2006; Nadeau

319 et al. 2017; Chiu et al. 2019a). Others, in particular members of the CYP6 family, may be

320 involved in pheromone biosynthesis (Chiu et al. 2019b), which may relate to variation in

321 pheromone production observed in different mountain pine beetle flight phenotypes (Jones et al.

322 2019). While many CYP9 functions have not yet been characterized (Keeling, Yuen, et al. 2013),

323 we identified three differentially expressed CYP9 genes that were associated with strong flight.

324 Other differentially expressed P450s in the CYP302 and CYP307 families may be related to the 
325 biosynthesis of hormones like 20E (Iga and Kataoka 2012), which may impact dispersal-related

326 behaviors, which is discussed in the following section.

327 Endocrine system. Trends in gene expression in strong flying female mountain pine beetles

328 indicate reduced levels of $\mathrm{JH}$, and increases in 20E, insulin, and IGF. These are important

329 hormones linked to dispersal and colonization in the mountain pine beetle. Reduced levels of JH

330 in strong fliers may act to maintain dispersal by preventing the onset of several colonization-

331 associated behaviors; during flight, JH epoxide hydrolase (JHEH), an enzyme that deactivates

$332 \mathrm{JH}$, is upregulated, likely reducing overall JH levels. In several insects, decreases in JH have

333 been linked to dispersal (Roff and Fairbairn 2007), however, increases in JH are linked to

334 reproductive behavior (Gruntenko and Rauschenbach 2008), biosynthesis of sex and aggregation

335 pheromones (Bridges 1982; Conn et al. 1984; Hall et al. 2002; Tittiger et al. 2003; Tillman et al.

336 2004), and degradation and reallocation of flight muscle resources (Borden and Slater 1969;

337 Sahota 1975). Similar phenomena occur in the mountain pine beetle (Mccambridge and Mata

338 1969) and may also be mediated by JH.

339 Increased interactions of insulin and insulin-like growth factors (IGF) were differentially

340 expressed and may be associated with metabolism and growth. In many bark beetles, including

341 the mountain pine beetle, strong dispersers tend to be larger (Evenden et al. 2014; Shegelski et

342 al. 2019). This may be influenced by increased IGF receptors (Nässel et al. 2015) and reduced

343 IGF binding protein levels (Alic and Partridge 2008). Insulin, which shares structural similarities

344 with IGF, affects carbohydrate and lipid metabolism (Erion and Sehgal 2013) and is likely one of

345 the metabolic hormones that increases metabolism in strong fliers. 
346 We also identified upregulation of ecdysone 20-monooxygenase, which catalyzes the production

347 of 20E (Nigg et al. 1976; Johnson and Rees 1977) and may affect flight behavior as it has links

348 to lipid metabolism (Wang et al. 2010), reproduction (Gruntenko and Rauschenbach 2008;

349 Sieber and Spradling 2015), and regulation of the circadian clock (Kumar et al. 2014).

350 Flight Behavior. Several differentially expressed genes may mediate response to abiotic and

351 biotic cues, affecting flight behavior. Strong fliers flew relatively more in the dark than weak

352 fliers (Fig. 2) which may be linked to differential expression of light-response and circadian

353 clock genes (Table S2). Nocturnin, which is downregulated in strong fliers, may affect response

354 to environmental light cues, as it mediates circadian light responses in Drosophila (Nagoshi et al.

355 2010). Flight patterns in strong fliers also appeared to be more aligned with actual day and night

356 (Fig. 2), which may be associated with differential response to a synchronized internal clock

357 (Wertman and Bleiker 2019). Also studied in Drosophila, circadian clock-controlled protein has

358 circadian-controlled expression (Lorenz et al. 1989) and is upregulated in mountain pine beetles

359 that are strong fliers. This, coupled with differential temporal flight performance, indicates

360 potential differences in circadian synchronization that may affect dispersal capacity.

361 Differentially expressed olfaction genes may also be important in determining dispersal

362 behavior. In the Douglas-fir beetle, Dendroctonus pseudotsugae, larger, stronger dispersers will

363 often ignore chemical cues (Bennett and Borden 1971), and this has similarly been observed in

364 the mountain pine beetle (Jones 2019). Several differentially expressed chemosensory proteins,

365 odorant receptors, and odorant-binding proteins, most of which are downregulated in strong

366 fliers, are potentially related to altered response to host volatiles, as occurs in another bark beetle,

367 Dendroctonus armandi (Zhang et al. 2016), and these may be of interest in understanding the 
368 role chemical cues play in flight and dispersal behavior. Some chemosensory genes may

369 influence flight behavior independent of chemosensory function (Jones et al. 2015); for example,

370 although the mechanisms are not yet understood, odorant-binding proteins in Helicoverpa

371 armigera have been linked to variation in flight activity, most likely through the use of lipids as

372 flight fuel (Wang et al. 2020).

373 Association study. We identified three SNPs associated with dispersal capacity: two linked to

374 total flight distance (Fig. 6A), and one linked to the number of times flight was initiated (Fig.

375 6B). Of these, one SNP associated with flight distance involved a synonymous change in an

376 exon. The other two SNPs were in non-coding regions. Synonymous SNPs may influence

377 genetic products (Kimchi-Sarfaty et al. 2007), and intronic SNPs can alter gene transcription

378 regulatory elements (Cooper 2010), but further research is needed to confirm causation and to

379 investigate mechanisms that may be involved in variable flight performance. One of the genes

380 containing a flight-associated SNP is uncharacterized. The other genes (protein Brunelleschi and

381 WD repeat-containing protein 55 homolog) do not currently have a known link to flight.

382 Regardless, SNP associations with flight capacity could provide a novel monitoring tool for

383 beetle management. Current mountain pine beetle surveying methods involve collecting disks

384 from the surface of infested trees to determine reproductive success of a population. These disks

385 often contain specimens that could be sequenced to detect markers of dispersal potential for that

386 population based on flight-related SNP phenotypes.

\section{Conclusion}

388 In conclusion, we identified genetic distinctions between mountain pine beetles with strong and 389 weak flight capacity but found no significant difference between weak and non-fliers. The 
390

391

392

393

394

395

396

397

398

399

400

401

402

403

404

405

406

407

408

409

410

genetic systems associated with sustained flight are likely to be involved in meeting the physiological demands of flight, while downregulated systems may represent mechanisms to conserve resources for post-flight host colonization. Our work quantifies genetic coordination between dispersal and colonization. Our research also identifies genes that may contribute to dispersal potential through flight-related behaviors, as well as genetic variants associated with flight performance. These genes may be used to predict flight capacity in outbreak beetle populations through genetic testing, and they may also inform studies on the heritable nature of dispersal capacity in bark beetles, which has yet to be investigated. This study sheds light on the physiological nature of dispersal by flight and indicates several potential avenues for future research.

\section{Acknowledgements}

The authors thank Julian Dupuis, Stephane Bordeleau, Jackson Lai, Dylan Sjølie, Phil Batista, Sebastian Lackey, Kelsey Jones, Antonia Musso, Devin Letourneau, Nathan Marculis, Melodie Kunegel-Lion, Janet Sperling and Stephen Trevoy for their help with sample collection, logistics, and advice on statistical analyses.

This research was enabled in part by support provided by Westgrid (www.westgrid.ca) and Compute Canada (www.computecanada.ca).

\section{Literature Cited}

Alic N, Partridge L. 2008. Stage debut for the elusive Drosophila insulin-like growth factor binding protein. J Biol. 7(6). doi:10.1186/jbiol79.

Armstrong JD, Texada MJ, Munjaal R, Baker DA, Beckingham KM. 2006. Gravitaxis in 
411 Drosophila melanogaster: A forward genetic screen. Genes, Brain Behav. 5(3).

412 doi:10.1111/j.1601-183X.2005.00154.x.

413 Bennett RB, Borden JH. 1971. Flight Arrestment of Tethered Dendroctonus pseudotsugae and 414 Trypodendron lineatum (Coleoptera: Scolytidae) in Response to Olfactory Stimuli1. Ann 415 Entomol Soc Am. 64(6). doi:10.1093/aesa/64.6.1273.

416 Blomquist GJ, Figueroa-Teran R, Aw M, Song M, Gorzalski A, Abbott NL, Chang E, Tittiger C. 417 2010. Pheromone production in bark beetles. Insect Biochem Mol Biol. 40(10).

418 doi:10.1016/j.ibmb.2010.07.013.

419 Bonnett TR, Robert JA, Pitt C, Fraser JD, Keeling CI, Bohlmann J, Huber DPW. 2012. Global 420 and comparative proteomic profiling of overwintering and developing mountain pine beetle,

421 Dendroctonus ponderosae (Coleoptera: Curculionidae), larvae. Insect Biochem Mol Biol. 42(12). 422 doi:10.1016/j.ibmb.2012.08.003.

423 Borden JH, Slater CE. 1969. Flight muscle volume change in Ips confusus (Coleoptera:

424 Scolytidae) . Can J Zool. 47(1). doi:10.1139/z69-006.

425 Bowler DE, Benton TG. 2005. Causes and consequences of animal dispersal strategies: Relating 426 individual behaviour to spatial dynamics. Biol Rev Camb Philos Soc. 80(2).

427 doi:10.1017/S1464793104006645.

428 Bradbury PJ, Zhang Z, Kroon DE, Casstevens TM, Ramdoss Y, Buckler ES. 2007. TASSEL:

429 Software for association mapping of complex traits in diverse samples. Bioinformatics. 23(19). 430 doi:10.1093/bioinformatics/btm308.

431 Bridges JR. 1982. Effects of Juvenile Hormone on Pheromone Synthesis in Dendroctonus 
432 frontalis. Environ Entomol. 11(2). doi:10.1093/ee/11.2.417.

433 Campbell EO, Davis CS, Dupuis JR, Muirhead K, Sperling FAH. 2017. Cross-platform

434 compatibility of de novo-aligned SNPs in a nonmodel butterfly genus. Mol Ecol Resour. 17(6).

435 doi:10.1111/1755-0998.12695.

436 Che R, Jack JR, Motsinger-Reif AA, Brown CC. 2014. An adaptive permutation approach for 437 genome-wide association study: Evaluation and recommendations for use. BioData Min. 7(1). 438 doi:10.1186/1756-0381-7-9.

439 Chiu CC, Keeling CI, Bohlmann J. 2019a. The cytochrome P450 CYP6DE1 catalyzes the 440 conversion of $\alpha$-pinene into the mountain pine beetle aggregation pheromone trans-verbenol. Sci 441 Rep. 9(1). doi:10.1038/s41598-018-38047-8.

442 Chiu CC, Keeling CI, Bohlmann J. 2019b. Cytochromes P450 Preferentially Expressed in 443 Antennae of the Mountain Pine Beetle. J Chem Ecol. 45(2). doi:10.1007/s10886-018-0999-0.

444 Conn JE, Borden JH, Hunt DWA, Holman J, Whitney HS, Spanier OJ, Pierce HD, Oehlschlager 445 AC. 1984. Pheromone production by axenically reared Dendroctonus ponderosae and Ips 446 paraconfusus (Coleoptera: Scolytidae). J Chem Ecol. 10(2). doi:10.1007/BF00987856.

447 Cooper DN. 2010. Functional intronic polymorphisms: Buried treasure awaiting discovery 448 within our genes. Hum Genomics. 4(5). doi:10.1186/1479-7364-4-5-284.

449 Cullingham CI, Cooke JEK, Dang S, Davis CS, Cooke BJ, Coltman DW. 2011. Mountain pine 450 beetle host-range expansion threatens the boreal forest. Mol Ecol. 20(10). doi:10.1111/j.1365$451 \quad 294 X .2011 .05086 . x$.

452 Danecek P, Auton A, Abecasis G, Albers CA, Banks E, DePristo MA, Handsaker RE, Lunter G, 
453 Marth GT, Sherry ST, et al. 2011. The variant call format and VCFtools. Bioinformatics. 27(15).

454 doi:10.1093/bioinformatics/btr330.

455 Erion R, Sehgal A. 2013. Regulation of insect behavior via the insulin-signaling pathway. Front 456 Physiol. 4 DEC. doi:10.3389/fphys.2013.00353.

457 Evenden ML, Whitehouse CM, Sykes J. 2014. Factors influencing flight capacity of the 458 mountain pine beetle (Coleoptera: Curculionidae: Scolytinae). Environ Entomol. 43(1). 459 doi:10.1603/EN13244.

460 Fraser JD, Bonnett TR, Keeling CI, Huber DPW. 2017. Seasonal shifts in accumulation of 461 glycerol biosynthetic gene transcripts in mountain pine beetle, Dendroctonus ponderosae 462 Hopkins (Coleoptera: Curculionidae), larvae. PeerJ. 2017(6). doi:10.7717/peerj.3284.

463 Gao X, Lee K, Reid MA, Sanderson SM, Qiu C, Li S, Liu J, Locasale JW. 2018. Serine 464 Availability Influences Mitochondrial Dynamics and Function through Lipid Metabolism. Cell 465 Rep. 22(13). doi:10.1016/j.celrep.2018.03.017.

466 Götz S, García-Gómez JM, Terol J, Williams TD, Nagaraj SH, Nueda MJ, Robles M, Talón M, 467 Dopazo J, Conesa A. 2008. High-throughput functional annotation and data mining with the 468 Blast2GO suite. Nucleic Acids Res. 36(10). doi:10.1093/nar/gkn176.

469 Gruntenko NE, Rauschenbach IY. 2008. Interplay of JH, 20E and biogenic amines under normal 470 and stress conditions and its effect on reproduction. J Insect Physiol. 54(6).

471 doi:10.1016/j.jinsphys.2008.04.004.

472 Hall GM, Tittiger C, Blomquist GJ, Andrews GL, Mastick GS, Barkawi LS, Bengoa C, Seybold 473 SJ. 2002. Male Jeffrey pine beetle, Dendroctonus jeffreyi, synthesizes the pheromone component 
474 frontalin in anterior midgut tissue. Insect Biochem Mol Biol. 32(11). doi:10.1016/S0965-

475 1748(02)00073-5.

476 Hart SJ, Schoennagel T, Veblen TT, Chapman TB, Franklin J. 2015. Area burned in the western

477 United States is unaffected by recent mountain pine beetle outbreaks. Proc Natl Acad Sci U S A.

478 112(14). doi:10.1073/pnas.1424037112.

479 Huber DPW, Robert JA. 2016. The Proteomics and Transcriptomics of Early Host Colonization 480 and Overwintering Physiology in the Mountain Pine Beetle, Dendroctonus ponderosae Hopkins 481 (Coleoptera: Curculionidae). In: Advances in Insect Physiology. Vol. 50.

482 Iga M, Kataoka H. 2012. Recent studies on insect hormone metabolic pathways mediated by 483 cytochrome P450 enzymes. Biol Pharm Bull. 35(6). doi:10.1248/bpb.35.838.

484 Johnson P, Rees HH. 1977. The mechanism of C 20 hydroxylation of $\alpha$ ecdysone in the desert 485 locust, Schistocerca gregaria. Biochem J. 168(3). doi:10.1042/bj1680513.

486 Jones CM, Papanicolaou A, Mironidis GK, Vontas J, Yang Y, Lim KS, Oakeshott JG, Bass C, 487 Chapman JW. 2015. Genomewide transcriptional signatures of migratory flight activity in a 488 globally invasive insect pest. Mol Ecol. 24(19). doi:10.1111/mec.13362.

489 Jones K. 2019. Influence of Semiochemical Cues on Mountain Pine Beetle Flight and 490 Subsequent Effect of Flight on Host Colonisation Processes. [Edmonton]: University of Alberta.

491 Jones KL, Shegelski VA, Marculis NG, Wijerathna AN, Evenden ML. 2019. Factors influencing 492 dispersal by flight in bark beetles (Coleoptera: Curculionidae: Scolytinae): From genes to 493 landscapes. Can J For Res. 49(9). doi:10.1139/cjfr-2018-0304.

494 Kanehisa M, Goto S. 2000. KEGG: Kyoto Encyclopedia of Genes and Genomes. Nucleic Acids 
495

496

497

498

499

500

501

502

503

504

505

506

507

508

509

510

511

512

513

514

515

Res. 28(1). doi:10.1093/nar/28.1.27.

Keeling CI, Chiu CC, Aw T, Li M, Henderson H, Tittiger C, Weng HB, Blomquist GJ,

Bohlmann J. 2013. Frontalin pheromone biosynthesis in the mountain pine beetle, Dendroctonus ponderosae, and the role of isoprenyl diphosphate synthases. Proc Natl Acad Sci U S A. 110(47). doi:10.1073/pnas.1316498110.

Keeling CI, Yuen MMS, Liao NY, Docking TR, Chan KSSK, Taylor GA, Palmquist DL, Jackman SD, Nguyen A, Li M, et al. 2013. Draft genome of the mountain pine beetle, Dendroctonus ponderosae Hopkins, a major forest pest. Genome Biol. 14(3). doi:10.1186/gb2013-14-3-r27.

Kim D, Pertea G, Trapnell C, Pimentel H, Kelley R, Salzberg SL. 2013. TopHat2: Accurate alignment of transcriptomes in the presence of insertions, deletions and gene fusions. Genome Biol. 14(4). doi:10.1186/gb-2013-14-4-r36.

Kimchi-Sarfaty C, Oh JM, Kim IW, Sauna ZE, Calcagno AM, Ambudkar S V., Gottesman MM. 2007. A "silent" polymorphism in the MDR1 gene changes substrate specificity. Science (80- ). 315(5811). doi:10.1126/science.1135308.

Kristensen NP, De Barro PJ, Schellhorn NA. 2013. The Initial Dispersal and Spread of an Intentional Invader at Three Spatial Scales. PLoS One. 8(5). doi:10.1371/journal.pone.0062407.

Kumar S, Chen D, Jang C, Nall A, Zheng X, Sehgal A. 2014. An ecdysone-responsive nuclear receptor regulates circadian rhythms in Drosophila. Nat Commun. 5. doi:10.1038/ncomms6697. de la Giroday HMC, Carroll AL, Aukema BH. 2012. Breach of the northern Rocky Mountain geoclimatic barrier: Initiation of range expansion by the mountain pine beetle. J Biogeogr. 39(6). 
doi:10.1111/j.1365-2699.2011.02673.x.

517 Langmead B, Salzberg SL. 2012. Fast gapped-read alignment with Bowtie 2. Nat Methods. 9(4).

518 doi:10.1038/nmeth.1923.

519 Laporte J, Blondeau F, Buj-Bello A, Mandel JL. 2001. The myotubularin family: From genetic

520 disease to phosphoinositide metabolism. Trends Genet. 17(4). doi:10.1016/S0168-

$5219525(01) 02245-4$.

522 Lawrence M, Huber W, Pagès H, Aboyoun P, Carlson M, Gentleman R, Morgan MT, Carey VJ.

523 2013. Software for Computing and Annotating Genomic Ranges. PLoS Comput Biol. 9(8).

524 doi:10.1371/journal.pcbi.1003118.

525 Leal SM. 2005. Detection of genotyping errors and pseudo-SNPs via deviations from Hardy-

526 Weinberg equilibrium. Genet Epidemiol. 29(3). doi:10.1002/gepi.20086.

527 Li H, Durbin R. 2009. Fast and accurate short read alignment with Burrows-Wheeler transform.

528 Bioinformatics. 25(14). doi:10.1093/bioinformatics/btp324.

529 Li H, Handsaker B, Wysoker A, Fennell T, Ruan J, Homer N, Marth G, Abecasis G, Durbin R.

530 2009. The Sequence Alignment/Map format and SAMtools. Bioinformatics. 25(16).

531 doi:10.1093/bioinformatics/btp352.

532 Liu H, Mardahl-Dumesnil M, Sweeney ST, O’Kane CJ, Bernstein SI. 2003. Drosophila

533 paramyosin is important for myoblast fusion and essential for myofibril formation. J Cell Biol.

534 160(6). doi:10.1083/jcb.200208180.

535 Lorenz LJ, Hall JC, Rosbash M. 1989. Expression of a Drosophila mRNA is under circadian

536 clock control during pupation. Development. 107(4). doi:10.1242/dev.107.4.869. 
537 Love MI, Huber W, Anders S. 2014. Moderated estimation of fold change and dispersion for 538 RNA-seq data with DESeq2. Genome Biol. 15(12). doi:10.1186/s13059-014-0550-8.

539 Marden JH, Fescemyer HW, Schilder RJ, Doerfler WR, Vera JC, Wheat CW. 2013. Genetic 540 variation in hif signaling underlies quantitative variation in physiological and life-history traits 541 within lowland butterfly populations. Evolution (N Y). 67(4). doi:10.1111/evo.12004.

542 Mccambridge WF, Mata SA. 1969. Flight muscle changes in black hills beetles, dendroctonus 543 ponderosae (Coleoptera: Scolytidae), during emergence and egg laying. Can Entomol. 101(5). 544 doi:10.4039/Ent101507-5.

545 Morgan M, Pagès H, Obenchain V, Hayden N. 2017. Binary alignment (BAM), FASTA, variant 546 call (BCF), and tabix file import. doi:10.18129/B9.bioc.Rsamtools.

547 Nadeau JA, Petereit J, Tillett RL, Jung K, Fotoohi M, MacLean M, Young S, Schlauch K, 548 Blomquist GJ, Tittiger C. 2017. Comparative transcriptomics of mountain pine beetle 549 pheromone-biosynthetic tissues and functional analysis of CYP6DE3. BMC Genomics. 18(1). 550 doi:10.1186/s12864-017-3696-4.

551 Nagoshi E, Sugino K, Kula E, Okazaki E, Tachibana T, Nelson S, Rosbash M. 2010. Dissecting 552 differential gene expression within the circadian neuronal circuit of Drosophila. Nat Neurosci. 553 13(1). doi:10.1038/nn.2451.

554 Nässel DR, Liu Y, Luo J. 2015. Insulin/IGF signaling and its regulation in Drosophila. Gen 555 Comp Endocrinol. 221. doi:10.1016/j.ygcen.2014.11.021.

556 Nigg HN, Svoboda JA, Thompson MJ, Dutky SR, Kaplanis JN, Robbins WE. 1976. Ecdysone 557 20-hydroxylase from the midgut of the tobacco hornworm (Manduca sexta L.). Experientia. 
558 32(4). doi:10.1007/BF01920781.

559 Niitepõald K, Smith AD, Osborne JL, Reynolds DR, Carreck NL, Martin AP, Marden JH,

560 Ovaskainen O, Hanski I. 2009. Flight metabolic rate and Pgi genotype influence butterfly

561 dispersal rate in the field. Ecology. 90(8). doi:10.1890/08-1498.1.

562 Paris JR, Stevens JR, Catchen JM. 2017. Lost in parameter space: a road map for stacks.

563 Methods Ecol Evol. 8(10). doi:10.1111/2041-210X.12775.

564 Peterson BK, Weber JN, Kay EH, Fisher HS, Hoekstra HE. 2012. Double digest RADseq: An

565 inexpensive method for de novo SNP discovery and genotyping in model and non-model species.

566 PLoS One. 7(5). doi:10.1371/journal.pone.0037135.

567 Pitt C, Robert JA, Bonnett TR, Keeling CI, Bohlmann J, Huber DPW. 2014. Proteomics

568 indicators of the rapidly shifting physiology from whole mountain pine beetle, Dendroctonus

569 ponderosae (coleoptera: Curculionidae), adults during early host colonization. PLoS One. 9(10).

570 doi:10.1371/journal.pone.0110673.

571 Pompella A, Visvikis A, Paolicchi A, De Tata V, Casini AF. 2003. The changing faces of

572 glutathione, a cellular protagonist. In: Biochemical Pharmacology. Vol. 66.

573 Portman SL, Felton GW, Kariyat RR, Marden JH. 2020. Host plant defense produces species-

574 specific alterations to flight muscle protein structure and flight-related fitness traits of two

575 armyworms. J Exp Biol. 223(16). doi:10.1242/jeb.224907.

576 R Core Team. 2017. R: A language and environment for statistical computing. https://www.r577 project.org/.

578 Raffa KF, Grégoire JC, Lindgren BS. 2015. Natural History and Ecology of Bark Beetles. In: 
579 Vega FE, Hofstetter RW, editors. Bark Beetles: Biology and Ecology of Native and Invasive 580 Species.

581 Rajkumar AP, Qvist P, Lazarus R, Lescai F, Ju J, Nyegaard M, Mors O, Børglum AD, Li Q, 582 Christensen JH. 2015. Experimental validation of methods for differential gene expression 583 analysis and sample pooling in RNA-seq. BMC Genomics. 16(1). doi:10.1186/s12864-015$584 \quad 1767-y$.

585 Robert JA, Bonnett T, Pitt C, Spooner LJ, Fraser J, Yuen MMS, Keeling CI, Bohlmann J, Huber 586 DPW. 2016. Gene expression analysis of overwintering mountain pine beetle larvae suggests 587 multiple systems involved in overwintering stress, cold hardiness, and preparation for spring 588 development. PeerJ. 2016(7). doi:10.7717/peerj.2109.

589 Robert JA, Pitt C, Bonnett TR, Yuen MMS, Keeling CI, Bohlmann J, Huber DPW. 2013. 590 Disentangling detoxification: Gene expression analysis of feeding mountain pine beetle 591 illuminates molecular-level host chemical defense detoxification mechanisms. PLoS One. 8(11). 592 doi:10.1371/journal.pone.0077777.

593 Rochette NC, Rivera-Colón AG, Catchen JM. 2019. Stacks 2: Analytical methods for paired-end 594 sequencing improve RADseq-based population genomics. Mol Ecol. 28(21). 595 doi:10.1111/mec.15253.

596 Roff DA, Fairbairn DJ. 2007. The evolution and genetics of migration in insects. Bioscience. 597 57(2). doi:10.1641/B570210.

598 Rosenberger DW, Venette RC, Aukema BH. 2016. Sexing live mountain pine beetles 599 Dendroctonus ponderosae: refinement of a behavioral method for Dendroctonus spp. Entomol 600 Exp Appl. 160(2). doi:10.1111/eea.12463. 
601 Safranyik L, Carroll AL. 2006. The biology and epidemiology of the mountain pine beetle in 602 lodgepole pine forests. Mt Pine Beetle - A Synth Biol Manag Impacts Lodg Pine. 11.

603 Sahota TS. 1975. Effect of juvenile hormone on acid phosphatases in the degenerating flight 604 muscles of the Douglas-fir beetle, Dendroctonus pseudotsugae. J Insect Physiol. 21(3). 605 doi:10.1016/0022-1910(75)90152-3.

606 Sandstrom P, Welch WH, Blomquist GJ, Tittiger C. 2006. Functional expression of a bark beetle 607 cytochrome P450 that hydroxylates myrcene to ipsdienol. Insect Biochem Mol Biol. 36(11). 608 doi:10.1016/j.ibmb.2006.08.004.

609 Segraves WA, Hogness DS. 1990. The E75 ecdysone-inducible gene responsible for the 75B 610 early puff in Drosophila encodes two new members of the steroid receptor superfamily. Genes 611 Dev. 4(2). doi:10.1101/gad.4.2.204.

612 Sheehan D, Meade G, Foley VM, Dowd CA. 2001. Structure, function and evolution of 613 glutathione transferases: Implications for classification of non-mammalian members of an 614 ancient enzyme superfamily. Biochem J. 360(1). doi:10.1042/0264-6021:3600001.

615 Shegelski VA, Evenden ML, Sperling FAH. 2019. Morphological variation associated with 616 dispersal capacity in a tree-killing bark beetle Dendroctonus ponderosae Hopkins. Agric For 617 Entomol. 21(1). doi:10.1111/afe.12305.

618 Sieber MH, Spradling AC. 2015. Steroid signaling establishes a female metabolic state and 619 regulates SREBP to control oocyte lipid accumulation. Curr Biol. 25(8). 620 doi:10.1016/j.cub.2015.02.019.

621 Singh SP, Coronella JA, Beneš H, Cochrane BJ, Zimniak P. 2001. Catalytic function of 
622 Drosophila melanogaster glutathione S-transferase DmGSTS1-1 (GST-2) in conjugation of lipid 623 peroxidation end products. Eur J Biochem. 268(10). doi:10.1046/j.1432-1327.2001.02179.x.

624 Steyn VM, Mitchell KA, Terblanche JS. 2016. Dispersal propensity, but not flight performance, 625 explains variation in dispersal ability. Proc R Soc B Biol Sci. 283(1836).

626 doi:10.1098/rspb.2016.0905.

627 Stinner RE, Barfield CS, Stimac JL, Dohse L. 1983. Dispersal and movement of insect pests. 628 Annu Rev Entomol Vol 28. doi:10.1146/annurev.en.28.010183.001535.

629 Tillman JA, Lu F, Goddard LM, Donaldson ZR, Dwinell SC, Tittiger C, Hall GM, Storer AJ, 630 Blomquist GJ, Seybold SJ. 2004. Juvenile hormone regulates De novo isoprenoid aggregation 631 pheromone biosynthesis in pine bark beetles, Ips spp., through transcriptional control of HMG632 CoA reductase. J Chem Ecol. 30(12). doi:10.1007/s10886-004-7945-z.

633 Tittiger C, Barkawi LS, Bengoa CS, Blomquist GJ, Seybold SJ. 2003. Structure and juvenile 634 hormone-mediated regulation of the HMG-CoA reductase gene from the Jeffrey pine beetle, 635 Dendroctonus jeffreyi. Mol Cell Endocrinol. 199(1-2). doi:10.1016/S0303-7207(02)00358-1.

636 Visscher PM, Wray NR, Zhang Q, Sklar P, McCarthy MI, Brown MA, Yang J. 2017. 10 Years 637 of GWAS Discovery: Biology, Function, and Translation. Am J Hum Genet. 101(1). 638 doi:10.1016/j.ajhg.2017.06.005.

639 Wang S, Liu S, Liu H, Wang J, Zhou S, Jiang RJ, Bendena WG, Li S. 2010. 20-

640 Hydroxyecdysone reduces insect food consumption resulting in fat body lipolysis during molting 641 and pupation. J Mol Cell Biol. 2(3). doi:10.1093/jmcb/mjq006.

642 Wang S, Minter M, Homem RA, Michaelson L V., Venthur H, Lim KS, Withers A, Xi J, Jones 
643 CM, Zhou JJ. 2020. Odorant binding proteins promote flight activity in the migratory insect, 644 Helicoverpa armigera. Mol Ecol. 29(19). doi:10.1111/mec.15556.

645 Wegener G. 1996. Flying insects: Model systems in exercise physiology. Experientia. 52(5). 646 doi:10.1007/BF01919307.

647 Wertman DL, Bleiker KP. 2019. Shedding new light upon circadian emergence rhythmicity in 648 the mountain pine beetle (Coleoptera: Curculionidae: Scolytinae). Can Entomol. 151(3). 649 doi:10.4039/tce.2019.18.

650 Wheat CW, Haag CR, Marden JH, Hanski I, Frilander MJ. 2010. Nucleotide polymorphism at a 651 gene (Pgi) under balancing selection in a butterfly metapopulation. Mol Biol Evol. 27(2).

652 doi:10.1093/molbev/msp227.

653 Wijerathna A, Evenden M. 2019. Energy use by the mountain pine beetle (Coleoptera:

654 Curculionidae: Scolytinae) for dispersal by flight. Physiol Entomol. 44(3-4).

655 doi:10.1111/phen.12290.

656 Yamamoto K, Hirowatari A, Shiotsuki T, Yamada N. 2016. Biochemical characterization of an 657 unclassified glutathione S-transferase of Plutella xylostella. J Pestic Sci. 41(4). 658 doi:10.1584/jpestics.D16-048.

659 Yamamoto K, Ichinose H, Aso Y, Banno Y, Kimura M, Nakashima T. 2011. Molecular 660 characterization of an insecticide-induced novel glutathione transferase in silkworm. Biochim 661 Biophys Acta - Gen Subj. 1810(4). doi:10.1016/j.bbagen.2011.01.003.

662 Zhan S, Zhang W, Niitepõld K, Hsu J, Haeger JF, Zalucki MP, Altizer S, De Roode JC, Reppert 663 SM, Kronforst MR. 2014. The genetics of monarch butterfly migration and warning colouration. 
664 Nature. 514(7522). doi:10.1038/nature13812.

665 Zhang R, Gao G, Chen H. 2016. Silencing of the olfactory co-receptor gene in Dendroctonus 666 armandi leads to EAG response declining to major host volatiles. Sci Rep. 6.

667 doi:10.1038/srep23136.

668 Zhang R, Chen J, Jiang L, Qiao G. 2019. The genes expression difference between winged and 669 wingless bird cherry-oat aphid Rhopalosiphum padi based on transcriptomic data. Sci Rep. 9. 670 doi:10.1038/s41598-019-41348-1

671 Zhou C, Wang L, Price M, Li J, Meng Y, Yue BS. 2020. Genomic features of the fall armyworm 672 (Spodoptera frugiperda) (J.E. Smith) yield insights into its defense system and flight capability. 673 Entomol Res. 50(2). doi:10.1111/1748-5967.12413. 
Figure 1

Summary of flight statistics from flight mill bioassays.

Groups represented include all flown beetles (AFB), association study beetles (ASB), RNA-Seq experiment beetles that demonstrated strong flight (RNA-S), and RNA-Seq beetles that demonstrated weak flight (RNA-W).
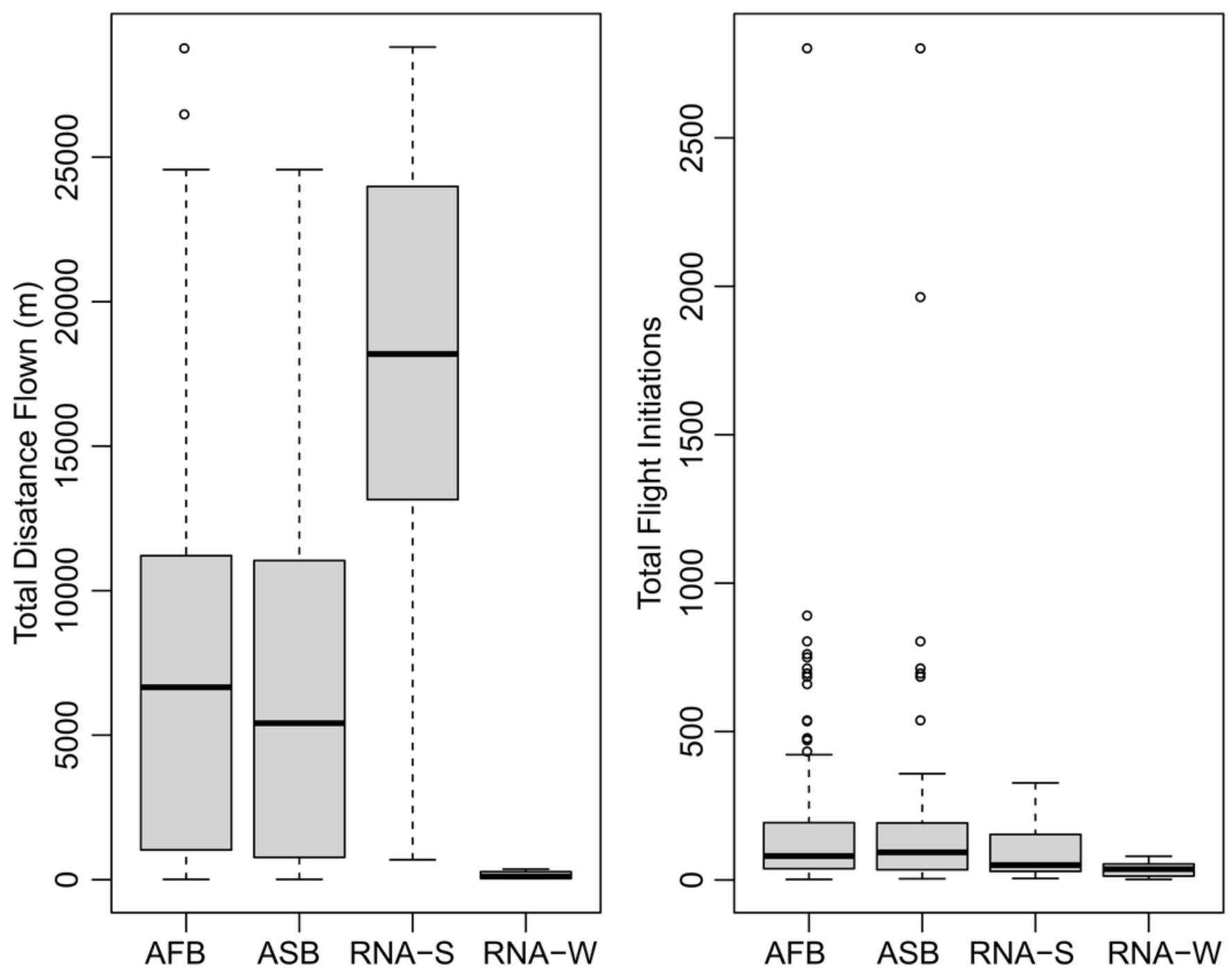
Figure 2

Individual flight patterns of strong fliers (A) and weak fliers (B).

The dashed red line indicates when lights were switched off in the flight room to simulate night, and the shaded box indicates actual night based on June 20th (dusk at 22:00, dawn at 05:00). Note that the scale of the $\mathrm{Y}$-axis is $10 \mathrm{x}$ less in (B), the weak flier graph, to allow for observable flight patterns. 

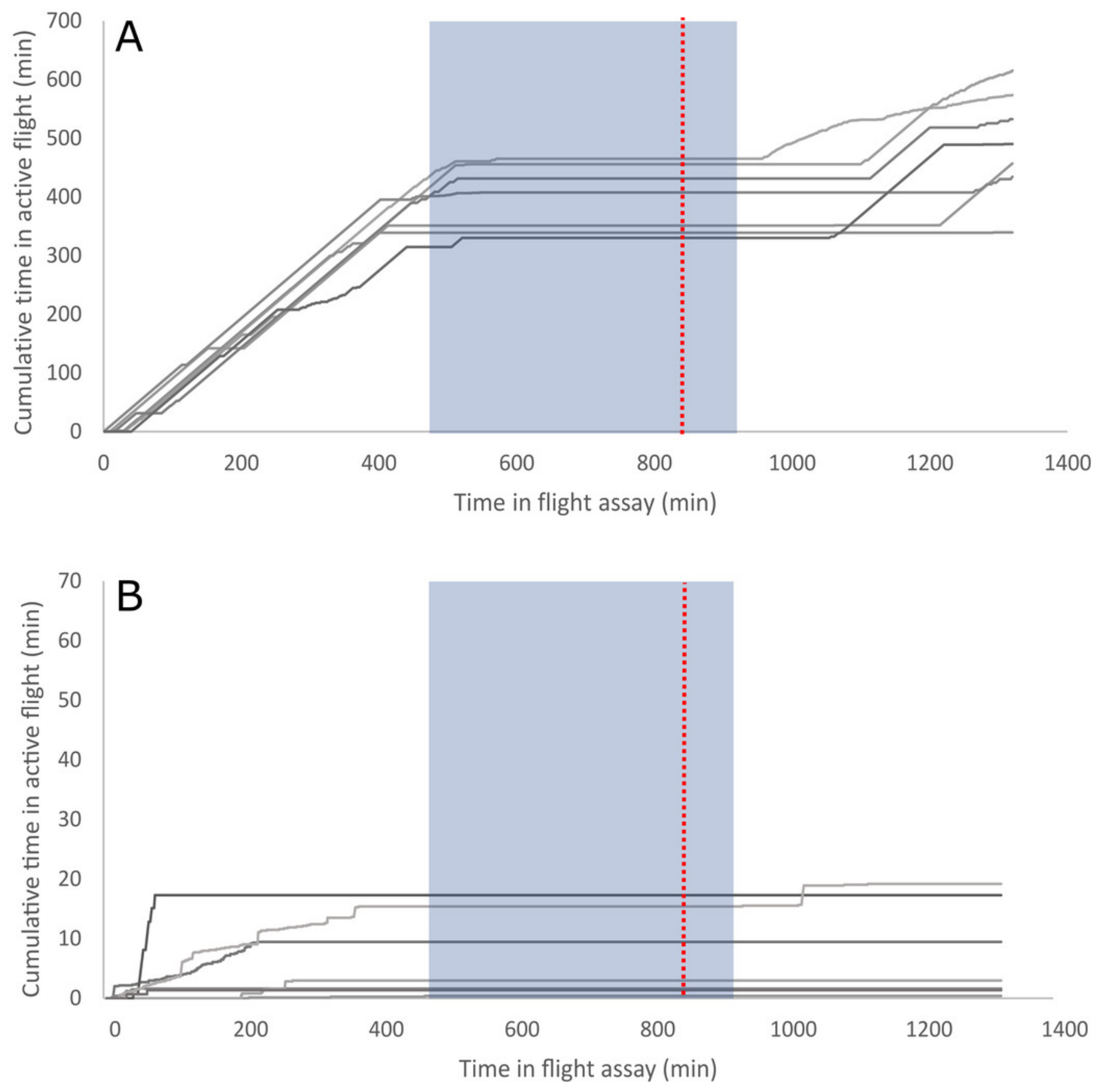


\section{Figure 3}

(A) rlog principal component analysis of variation in gene expression in the three flight groups.

Ellipses show 95\% confidence intervals. (B) The log ratio vs mean average plot (MA plot) shows differential expression analysis between weak and non-fliers. There were no genes significantly differentially expressed with flight at $\alpha=0.01$. (C) MA plot shows differential expression analysis between strong and weak fliers. Significant differentially expressed genes with flight $(\alpha=0.01)$ are shown in red.
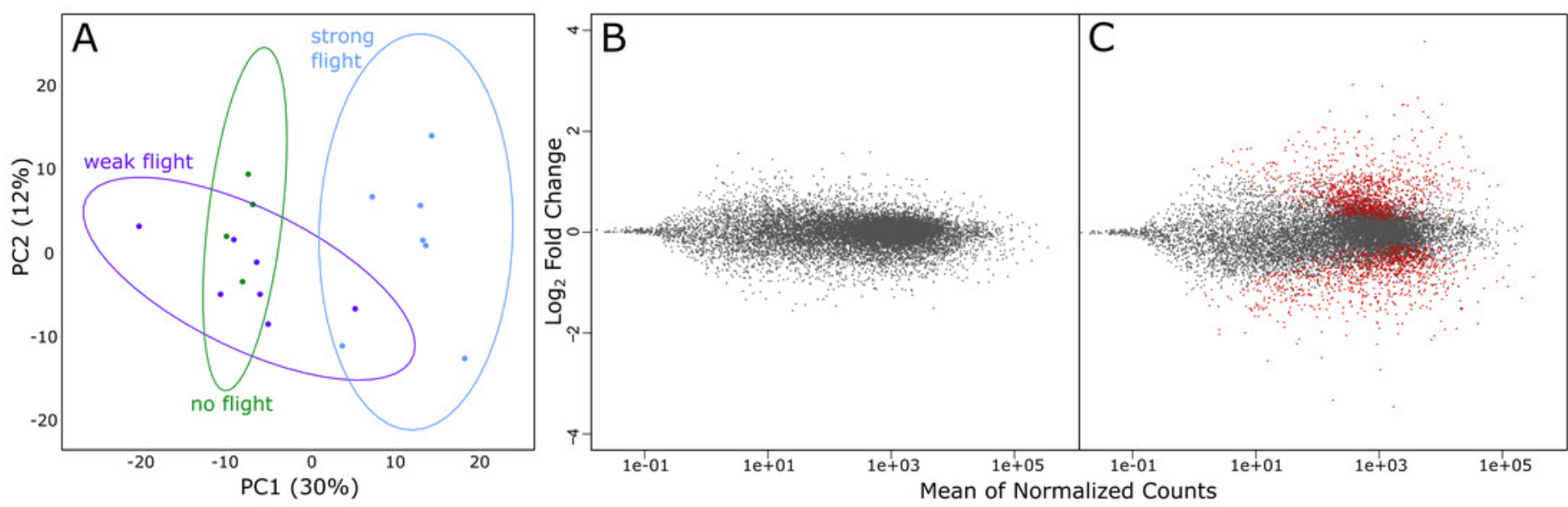


\section{Figure 4}

GO (Gene Ontology) enrichment analysis reduced to most specific terms where possible.

All GO annotations shown were significantly different between strong and weak fliers $(F D R=0.05)$. Pie charts show proportions represented in the total number of sequences relating to differentially expressed GO terms.

\section{Upregulated Molecular Functions}

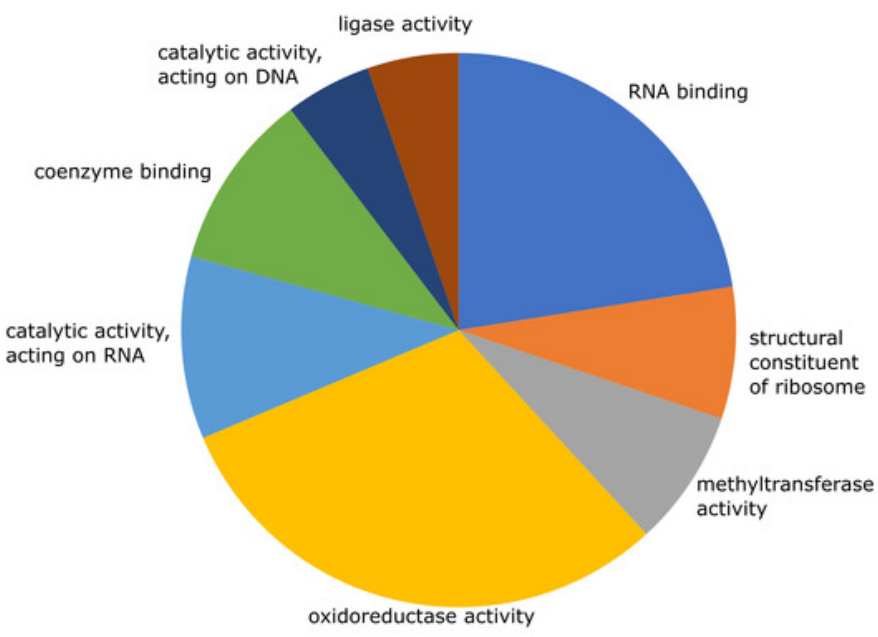

Downregulated Molecular Functions

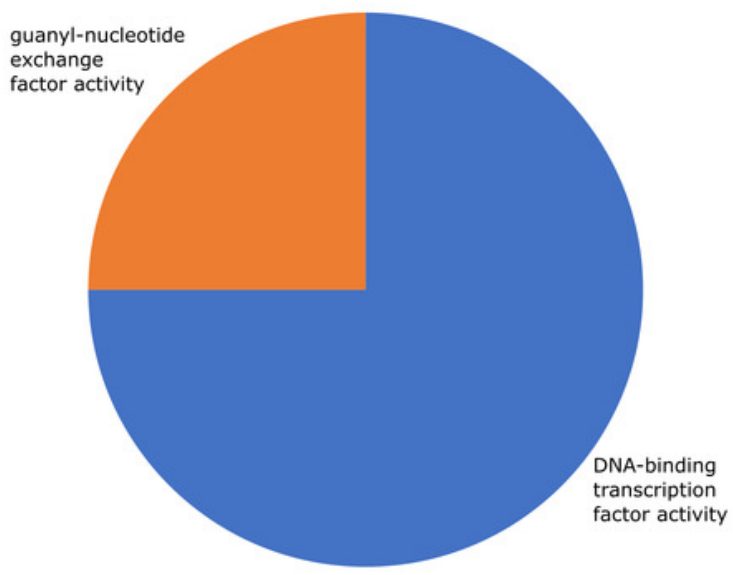

\section{Upregulated Biological Processes}

nucleic acid

phosphodiester pigment

regulation of mitotic phosphodiester biosynthetic

metaphase/anaphase bond hydrolysis process

mitochondrion organization

coenzyme metabolic process

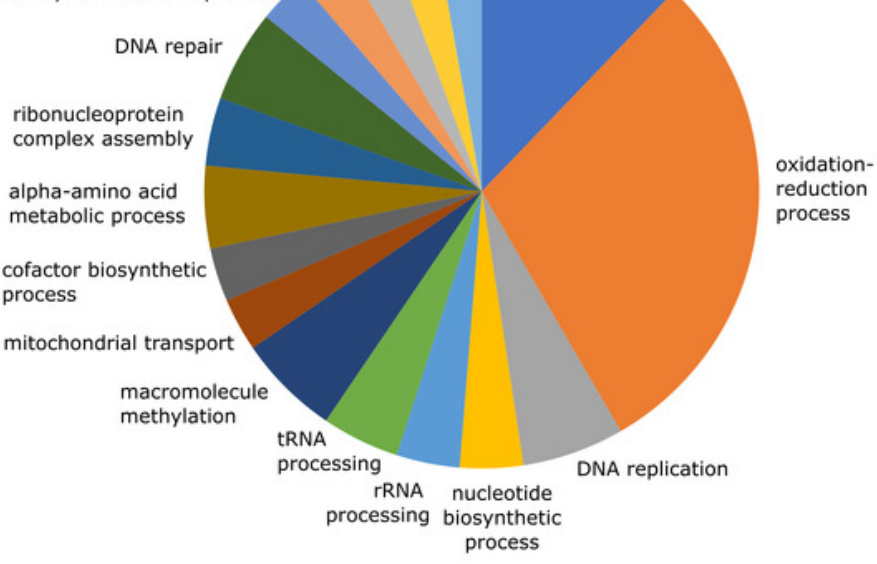

Downregulated Biological Processes

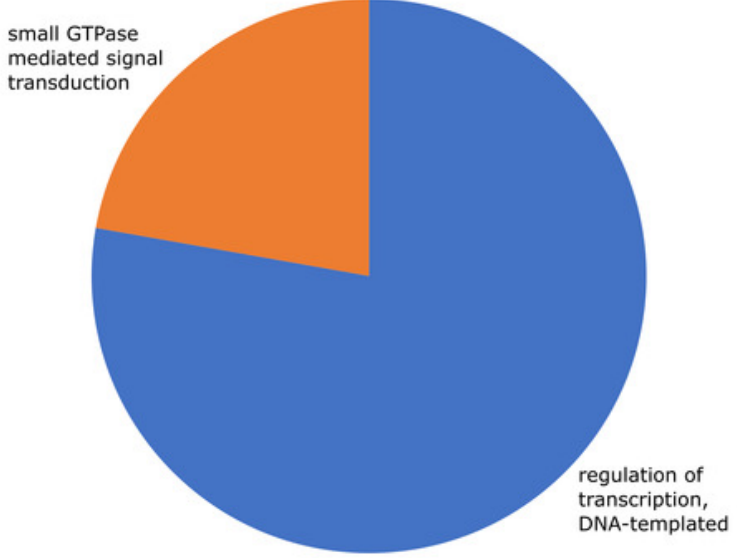


Figure 5

Representation of KEGG (Kyoto Encyclopedia of Genes and Genomes) pathways with more than three differentially expressed genes.

Blue shows number of enzymes of a pathway represented in our data, and orange shows the total number of sequences related to enzymes in the pathway. Pathways with $>60$ sequences have been truncated. 


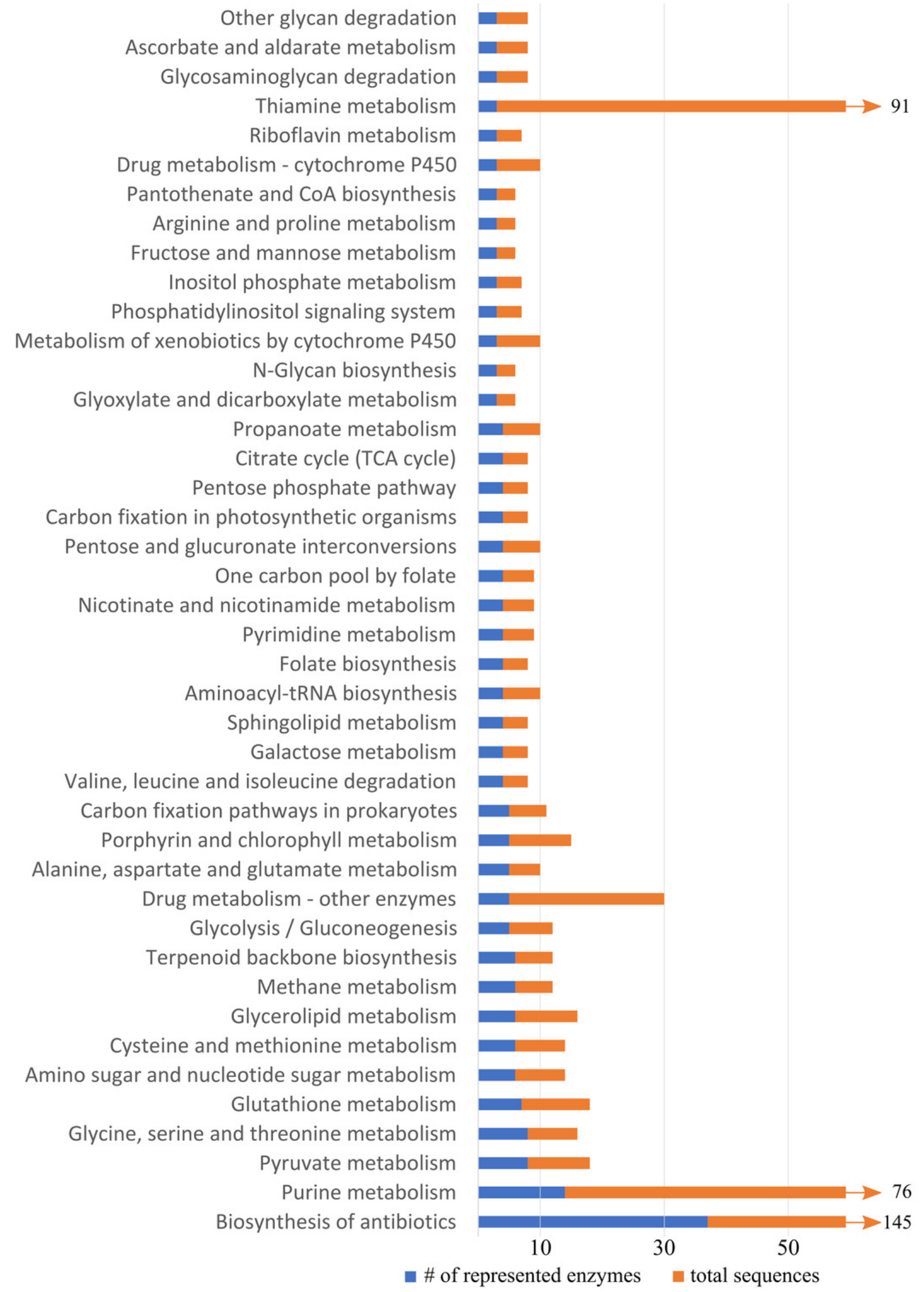


Figure 6

Manhattan plots showing - $\log _{10}$ permutation test $p$-values for each SNP based on testing for association with $(A)$ total distance flown and $(B)$ the total number of times flight was initiated.

SNPs are shaded by scaffold, alternating between black and white, the dashed red line indicates the threshold of significance based on a permutation test $p$-value of 0.05 , and purple circles indicate SNPs significantly associated with the tested traits.

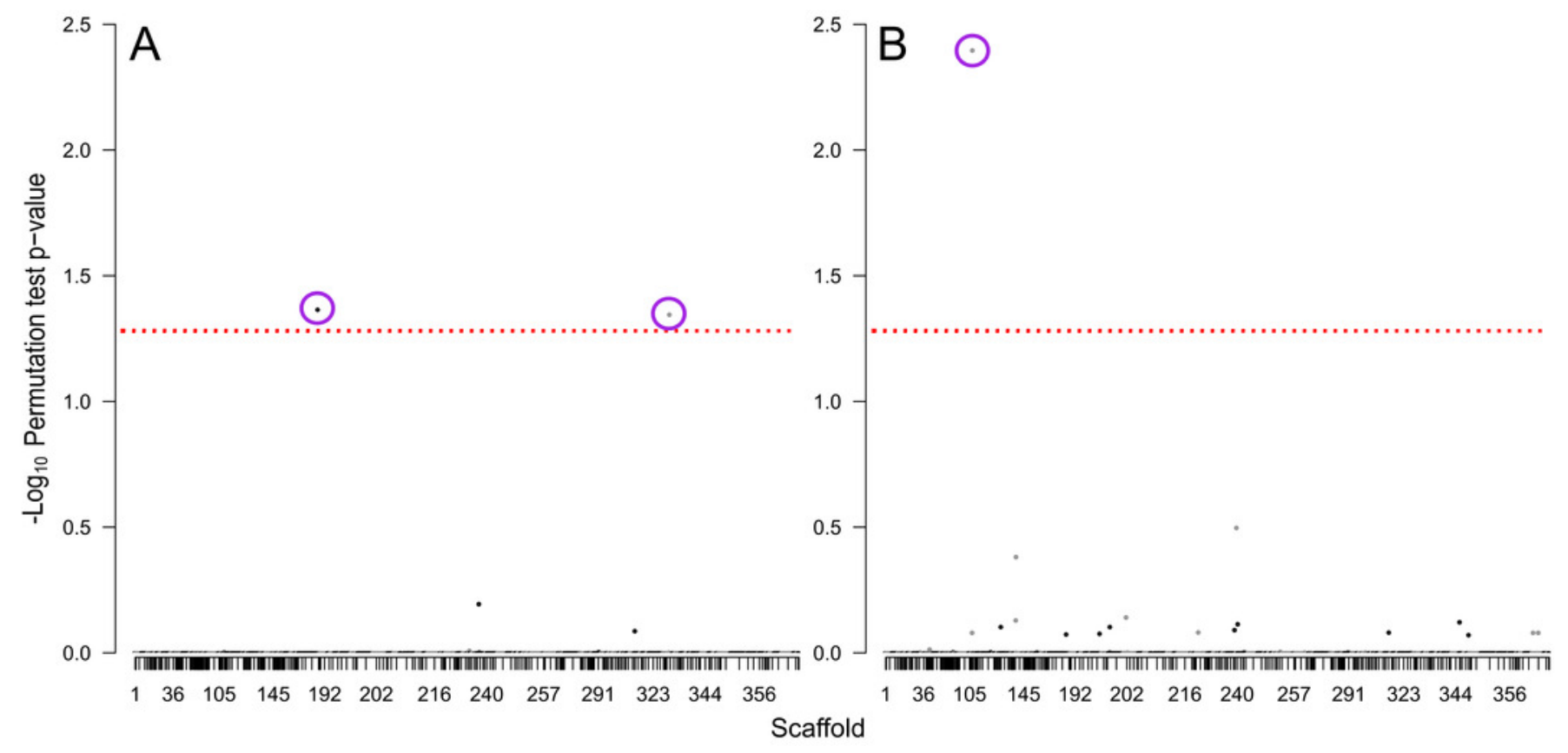




\section{Table 1 (on next page)}

Summaries of flight and sequence data for each sample group. 


\begin{tabular}{|c|c|c|c|c|c|c|c|c|c|c|}
\hline $\begin{array}{l}\text { Beetle } \\
\text { Group }\end{array}$ & $n$ & $\begin{array}{c}\text { Average } \\
\text { flight } \\
\text { distance } \\
(\mathrm{km})\end{array}$ & $\begin{array}{l}\text { Minimum } \\
\text { flight } \\
\text { distance } \\
(\mathrm{km})\end{array}$ & $\begin{array}{l}\text { Maximum } \\
\text { flight } \\
\text { distance } \\
(\mathrm{km})\end{array}$ & $\begin{array}{l}\text { Average } \\
\text { number } \\
\text { of flights }\end{array}$ & $\begin{array}{l}\text { Minimum } \\
\text { number } \\
\text { of flights }\end{array}$ & $\begin{array}{c}\text { Maximum } \\
\text { number of } \\
\text { flights }\end{array}$ & $\begin{array}{l}\text { Average } \\
\text { number } \\
\text { of reads } \\
\text { (millions) } \\
(>\mathrm{Q} 30)\end{array}$ & $\begin{array}{l}\text { Minimum } \\
\text { number } \\
\text { of reads } \\
\text { (millions) } \\
(>\mathrm{Q} 30)\end{array}$ & $\begin{array}{c}\text { Maximum } \\
\text { number of } \\
\text { reads } \\
\text { (millions) } \\
(>\mathrm{Q} 30)\end{array}$ \\
\hline All flown & 124 & 7.40 & 0.01 & 28.81 & 176.00 & 2 & 2806 & - & - & - \\
\hline
\end{tabular}

Beetles used for RNA-Seq

All

beetles

$14 \quad 10.08$

$10.08-0.04$

Weak

fliers

Strong

fliers

7

$$
0.23
$$

$0.04 \quad 28.81$

72.80

2

327

65.57

$25.17 \quad 108.83$

Non-

7

19.90

0.04

0.69

61.70

2

210

67.14

$44.32 \quad 91.50$

fliers

4

0.00

$9.90 \quad 28.81$

83.90

5

327

61.48

25.17

77.15

Beetles used for flight association study

All

beetles

59

$$
6.38
$$

0.01

$24.57 \quad 229.83$

4

2806

1.32

1.32

1.32

Weak

28

838.31

10.36

$3666.26 \quad 164.36$

4

1968

1.30

0.68

2.17

Strong

2806

1.35

0.32

1.73 